\title{
UPACARA MAMAPAS LEWU PADA MASYARAKAT HINDU KAHARINGAN DI DESA PETAK BAHANDANG KECAMATAN TASIK PAYAWAN KABUPATEN KATINGAN
}

\author{
Suwito \\ Institut Agama Hindu Negeri Tampung Penyang Palangkaraya \\ bawiayahfda@gmail.com
}

$\begin{array}{ll}\text { Riwayat Jurnal } & \\ \text { Artikel diterima } & :- \\ \text { Artikel direvisi } & :- \\ \text { Artikel disetujui } & :-\end{array}$

\section{Abstrak}

Upacara Mamapas Lewu akibat perzinahan adalah merupakan bagian dari sikap dan tingkah laku baik dalam pelaksanaan upacara menetralisirkan segala hal-hal yang tidak baik, malapetaka, marabahaya bagi kehidupan manusia serta memohon berkat perlindungan dan anugrah dari Ranying Hatalla Langit (Tuhan Yang Maha Esa) agar dalam kehidupan keluarga maupun masyarakat desa mendapatkan kesejahteraan, kedamaian dan keselamatan yang melibatkan masyarakat sekitarnya. Kegiatan tersebut merupakan sesuatu yang selalu dilakukan oleh masyarakat Hindu Kaharingan bahkan masyarakat secara umum juga meyakini ajaran tersebut, karena ingin mendapatkan keselamatan. Dengan dilakukan upacara Mamapas Lewu akibat perzinahan sebagai salah satu upacara untuk menetralisir atau menghapuskan segala hal peristiwa yang terjadi pada kehidupan manusia yang didasari dengan simbol, mitos dan ritus.

Tatacara upacara mamapas lewu akibat perzinahan adalah diawali dengan mempersiapkan sarana dan prasarana upacara, setelah beberapa sarana tersebut telah dipersiapkan, maka seluruh keluarga dan masyarakat yang melaksanakan upacara tersebut bersama-sama mendirikan Pasah Pali tersebut di Pinggir Sungai. Hal itu dilakukan secara bergotong royong (habaring hurung) bersama masyarakat sekitarnya. Setelah itu baru upacara mamapas lewu akibat perzinahan dilaksanakan mulai dari pisor melaksanakan duduk menawur (Hataburan Bulau Urai) menuju Ganan Pali dengan mempersembahkan sesajen agar tidak mengganggu lagi. Fungsi upacara mamapas lewu akibat perzinahan adalah mempunyai fungsi yang bertujuan untuk menciptakan keseimbangan, keharmonisan dan keselamatan dunia. Makna upacara mamapas lewu akibat perzinahan pada hakikatnya adalah sebagai perwujudan simbol-simbol ketuhanan yang mempunyai makna yang tinggi dalam hal manusia memuja kebesaran Tuhan beserta semua manifestasinya, karena segala yang akan terjadi di karenakan atas kehendak Ranying Hatalla (Tuhan Yang Maha Esa). Makna tersebut dapat ditinjau dari makna sasajen dan ritualnya.

Kata Kunci : Upacara, Mamapas Lewu Akibat Perzinahan 


\section{Pendahuluan}

Di Kalimantan Tengah terdapat berbagai jenis ritual yang diyakini dan dilaksanakan oleh masyarakat Hindu Kaharingan, salah satunya adalah upacara mamapas lewu. Upacara mamapas lewu ini makin langka dilaksanakan, karena pemahaman masyarakat Hindu Kaharingan terhadap ritual tersebut sangat kurang dan sering menganggap hal-hal yang biasa, sedangkan upacara tersebut sangat penting sekali setelah ada masalah seperti terjadi perkelahian,bencana banjir berladang tidak berhasil, buah-buahan tidak menjadi. Hal tersebut sehingga muncul penderitaan dan kemiskinan yang mengakibatkan kelaparan dan penderitaan bagi masyarakat setempat. Upacara mamapas lewu yaitu upacara ritual yang dilaksanakan oleh Pisor akibat perbuatan yang dilakukan oleh seorang laki-laki menghamili seorang perempuan tetapi tidak bertanggung jawab. Hal tersebut sehingga menjadi suatu pertanda/peringatan bahwa kehidupan ini adanya kekuatan-kekuatan ajaib yang dapat mempengaruhi dan menguasai alam serta kehidupan manusia itu sendiri. Dengan dilakukan upacara mamapas lewu sebagai salah satu upacara untuk menetralisir atau menghapuskan segala hal yang terjadi pada kehidupan manusia yang didasari dengan simbol, mitos, dan ritus. Dalam Kitab Suci Panaturan Pasal 41 ayat 5 menyatakan bahwa :

Kuan Raja Uju Hakanduang kakare ketun ije muhun te kareh, manumun auh ije jadi inukas awi Ranying Hatalla iete Raja Tunggal Sangumang, Raja Mantir Mamaluhing Bungai, Raja Linga Rawing Tempun Telun, ketun majar ampin talatah gawin balian, bara balian Tantulak Dahyang Baya, Balian Manyaki, Balian Mambuhul, Balian Balaku Untung, tuntang kakare ajar ije beken kea.

Artinya :

Raja Uju Hakanduang berkata, kalian yang turun itu nanti, sebagaimana yang difirmankan Ranying Hatalla yaitu Raja Tunggal Sangumang, Raja Mantir Mamaluhing Bungai, Raja Linga Rawing Tempun Telun, kalian mengajarkan tatacara pelaksanaan balian, dari balian Tantulak Dahyang Baya, Balian Manyaki, Balian Mambuhul, Balian Balaku Untung, serta ajaran-ajaran upacara lainnya.

Sebagaimana hal yang tertulis dalam ayat tersebut diatas, maka tergambarlah bahwa proses upacara mamapas lewu pada awalnya dilaksanakan dengan menggunakan Balian atau Tawur. Balian/Tawur 
Tantulak Dahyang Baya ini adalah berdasarkan ajaran Bawi Ayah. Ajaran tersebut dilakukan sesuai dengan istilah orang Dayak Di mana bumi di pijak di situ langit di junjung yaitu Ekae (Tempat), Katika (Waktu) dan Hampea (Kapan) atau dalam ajaran agama Hindu konsep Desa Kala Patra (tempat, waktu, keadaan) daerah setempat, seperti di daerah Katingan ada perbedaan proses pelaksanaan upacara mamapas lewu, karena menyesuaikan daerah Katingan tidak menggunakan Balian akan tetapi hanya menggunakan Tawur yang dilaksanakan oleh Pisor. Perbedaan tersebut tidak menjadi persoalan bagi masyarakat Kalimantan Tengah pada umumnya dan masyarakat Kabupaten Katingan pada khususnya, karena tujuan dan maknanya itu sama dan perbedaan tersebut menunjukan suatu keindahan bagi masyarakat Kabupaten Katingan. Bagi pemeluk masyarakat Kaharingan upacara mamapas lewu merupakan tradisi yang lahir dari adat kebiasaan nenek moyang, yang menjadi tuntutan kewajiban suci yang dilaksanakan dan merupakan suatu kepercayaan/keyakinan sebagai salah satu ibadah masyarakat Hindu Kaharingan.

\section{Pembahasan}

\subsection{Pengertian Upacara Mamapas Lewu}

Menurut Pendapat Pisor Udie (wawancara tanggal 5 Oktober 2016) bahwa mamapas lewu adalah "membersihkan desa dengan cara ritual dari segala hal yang sifatnya tidak baik sehingga berdampak kepada masyarakat setempat". Sementara menurut pendapat Pisor Abar (Wawancara tanggal 6 Oktober 2016) mengatakan mamapas Lewu adalah "suatu kegiatan yang dilakukan oleh masyarakat setempat dengan menggunakan ritual Agama Hindu kaharingan dengan tujuan untuk menetralisir desa dari pengaruh-pengaruh roh jahat yang dapat membuat masyarakat setempat menjadi miskin." Dari kedua pendapat tersebut diatas dapat disimpulkan bahwa Upacara Mamapas Lewu adalah Suatu Upacara yang dilaksanakan oleh masyarakat setempat guna menetralisir Desa dari pengaruhpengaruh roh jahat yang disebab oleh olahnya manusia, yang dilaksanakan dengan tatacara ritual Agama Hindu Kaharingan. 
Menurut Pendapat Pisor Udie (wawancara tanggal 5 Oktober 2016) bahwa mamapas lewu akibat perzinahan adalah "suatu upacara ritual yang dilaksanakan oleh masyarakat desa akibat perbuatan yang dilakukan oleh seorang laki-laki yang menghamili seorang perempuan dengan tidak bertanggung jawab." Sementara menurut pendapat Pisor Abar (Wawancara tanggal 6 Oktober 2016) mengatakan bahwa mamapas lewu akibat perzinahan adalah "suatu upacara secara tiba-tiba atau mendadak yang dilakukan oleh masyarakat setempat dengan menggunakan ritual Agama Hindu kaharingan akibat olahnya seorang lakilaki yang tidak bertanggung jawab menghamili seorang perempuan." Sementara menurut pendapat Amisran,S.Ag Ketua Majelis Kelompok Agama Hindu Kaharingan Desa Petak Bahandang Kecamatan Tasik Payawan Kabupaten Katingan (wawancara tanggal 5 oktober 2016) bahwa Upacara Mamapas lewu akibat perzinahan adalah". Upacara yang sifatnya spontanitas yang dilaksanakan oleh masyarakat akibat perbuatan seorang lakilaki yang menghamili seorang perempuan tetapi tidak bertanggung jawab. Sedangkan menurut pendapat Gadi (wawancara tanggal 6 Oktober 2016) Seorang tokoh masyarakat sekaligus sebagai Mantir Adat Desa Petak Bahandang Kecamatan Tasik Payawan Kabupaten Katingan mengatakan bahwa Upacara mamapas lewu akibat perzinahan adalah "suatu upacara yang dilakukan oleh masyarakat setempat yang sifatnya tiba-tiba dan dilaksanakan dengan cara ritual Agama Hindu Kaharingan”. Dari beberapa pendapat tersebut di atas dapat disimpulkan bahwa upacara mamapas lewu akibat perzinahan adalah Suatu upacara yang dilaksanakan oleh masyarakat setempat dengan upacara ritual Agama Hindu Kaharingan guna menetralisir desa dari pengaruh-pengaruh roh jahat yang disebabkan oleh perbuatan seorang laki-laki yang menghamili seorang perempuan, sehingga mengakibatkan masyarakat setempat menjadi miskin.

\subsection{Pelaksanaan Upacara Mamapas Lewu Akibat Perzinahan pada Masyarakat Hindu Kaharingan}

Berdasarkan penjelasan dari Pisor Udie bahwa pelaksanaan upacara Mamapas Lewu bagi masyarakat Hindu 
Kaharingan di Desa Petak Bahandang Kecamatana Tasik Payawan Kabupaten Katingan memegang peranan sangat penting untuk menetralisir segala hal yang tidak baik. Dalam pelaksanaan upacara mamapas lewu selalu menyesuaikan dengan masalah yang terjadi, karena dalam ajaran Agama Hindu Kaharingan di Desa Petak Bahandang Kecamatan Tasik Payawan Kabupaten Katingan mengenal beberapa jenis upacara mamapas lewu sebagai berikut :

1) Mamapas Lewu tahunan

2) Mamapas Lewu akibat perzinahan

3) Mamapas Lewu akibat kawin salah silsilah

Dari ke tiga jenis Upacara Mamapas Lewu tersebut diatas Upacara Mamapas Lewu akibat perzinahan dan salah silsilah inilah yang paling berdampak bagi masyarakat setempat. Secara ritual keagamaan yang diyakini oleh masyarakat Hindu Kaharingan di Desa Petak Bahandang Kecamatan Tasik Payawan Kabupaten Katingan bahwa upacara Mamapas Lewu tahunan tersebut dilaksanakan setiap tahun. Dalam tulisan sangat tertarik mengangkat Upacara Mamapas Lewu akibat perzinahan.
Menurut pendapat Pisor Udie bahwa yang dimaksud dengan upacara mamapas lewu akibat perzinahan yaitu suatu upacara yang dilaksanakan secara tibatiba dan paksa yang dilakukan oleh warga desa dan tokoh masyarakat diawali dengan :

1. Persiapan pelaksanaan upacara.

Dalam pelaksanaan upacara mamapas lewu akibat perzinahan, masyarakat bersama mantir adat bermusyawarah untuk memufakatkan pelaksanaan upacara tersebut, terutama menyangkut hewan kurbannya. Apakah sistemnya secara paksaan dibunuh atau diberitahu kepada pihak laki-laki. Setelah ada mufakat dari masyaraakat dan mantir adat barulah dilanjutkan ketahap selanjutnya.

2. Persiapan sarana prasarana

Dalam pelaksanaan upacara mamapas lewu akibat perzinahan perlu dipersiapkan sarana prasarana serta sesajen. Adapun sarana dan prasarana serta sesajen yang harus dipersiapkan adalah sebagai berikut :

1) Amak ukan munduk manawur (tikar tempat duduk manawur).

2) Tambak hambaruan.

3) Urak ice kawak (Babi satu ekor)

4) Manuk ice kawak (Ayam satu ekor)

5) Tampung papas 
6) Dahan urak (darah babi)

7) Pasah pali (Rumah tempat menyimpan sesajen)

8) Baram (tuak)

9) Bari baputi

10) Bari pulut

11) Wadai cucur lime

12) Wadai apam limkawake kawak

13) Wadai gagatas lime kawak

14) Ketupat sinta telu kawak

15) Ketupat manuk telu kawak

16) Ketupat sukup telu kawak

17) Lamang lime katetek

18) Kate manuk ice kawak

19) Sipa lime

20) Ruku lime

Adapun tatacara upacara mamapas lewu akibat perzinahan adalah diawali dengan mempersiapkan sarana dan prasarana upacara, setelah beberapa sarana tersebut telah dipersiapkan, maka seluruh keluarga yang melaksanakan upacara tersebut bersama-sama mendirikan pasah pali tersebut di pinggir sungai, hal itu dilakukan secara bergotong royong (habaring hurung) bersama masyarakat sekitarnya. Setelah itu baru upacara mamapas lewu dilaksanakan mulai dari pisor melaksanakan duduk menawur (Hataburan Bulau Urai) menuju ganan pali dengan mempersembahkan sesajen agar tidak mengganggu lagi.
Tradisi upacara mamapas lewu akibat perzinahan ini dipercayakan sebagai salah satu sarana untuk menetralisir atau pensucian dan penghapusan dari segala malapetaka, marabahaya yang menimpa keluarga dan masyarakat setempat. Sehingga setiap tahapan pelaksanaannya selalu mengacu pada makna Ketuhanannya berdasarkan pemujaan-pemujaan yang pertama kepada manifestasi beliau maupun secara khususnya puja atau mantram ditujukan kepada-Nya.

\subsection{Fungsi Upacara Mamapas Lewu akibat Perzinahan Bagi Masyarakat Hindu Kaharingan}

Menurut Pisor Udie upacara mamapas lewu akibat perzinahan adalah terbagi dua fungsi religius dan fungsi sosial yang merupakan suatu sistem dari unsur kebudayaan dalam hal ini fungsi upacara keagamaan. Fungsi religius yang pertama merupakan sarana ekspresi simbolis untuk mewujudkan konsepsikonsepsi keagamaan, khususnya yang berkenaan dengan kekuatan-kekuatan gaib tertentu, sedangkan fungsi yang kedua merupakan ekspresi simbolis untuk menyalurkan tanggapan-tanggapan kesan atas alam beserta sifat-sifatnya maupun 
atas konsep budaya tertentu melalui kekuatan visual yang terencana (wawancara 5 Oktober 2016).

Segala tindakan yang dilakukan manusia dalam realitas hidup penuh dengan simbol yang mempunyai fungsi bagi orang yang melakukan atau orang dalam suatu kelompok yang mungkin orang lain belum tahu. Sistem sosial masyarakat yang terdiri dari beberapa bagian sub sistem mempunyai fungsi tertentu yang membentuk struktur sosial untuk kelangsungan dan keseimbangan masyarakat secara harmonis. Upacara Pakanan Dahyang adalah suatu tindakan budaya manusia yang tercipta dari berbagai struktur masyarakat yang terbentuk dalam interaksi sosial mempunyai fungsi dan tujuan yang luhur dalam menciptakan keseimbangan dan keharmonisan serta keselamatan dalam kehidupan manusia itu sendiri.

Sesuai teori religi upacara mamapas lewu akibat perzinahan pada masyarakat Hindu Kaharingan di Desa Petek Bahandang Kecamatan Tasik Payawan Kabupaten Katingan mempunyai fungsi yang tinggi dalam kehidupan manusia, karena pelaksanaan terjadi adanya interaksi sosial masyarakat yang mempunyai hubungan dan melengkapi dalam setiap fungsinya, bahwa kepercayaan yang dikemukakan dalam totemisme bukanlah hal yang terpenting tentang totemisme tetapi ritual-lah yang terpenting. Lebih lanjut ia menjelaskan, dalam pandangan Durkheim "cult" (dari kata latin cultus "pemujaan") yang terdiri atas peristiwa-peristiwa tertentu adalah inti kehidupan bersama suatu klan. Artinya upacara-upacara yang dilakukan oleh masyarakat merupakan suatu tindakan kehidupan yang tidak bisa ditinggalkan. Hal itu sesuai dengan pandangan agama Hindu bahwa hidup adalah suatu yajna (korban) atau pemujaan yang harus dilakukannya sepanjang masa, karena alam semesta termasuk manusia diciptakan tuhan dengan yajna. Sebagai balas budi dan rasa bakti manusia melaksanakan yajna (upacara) kepada tuhan beserta segala makhluk ciptaannya demi tercipta kehidupan yang harmonis. Dimanapun ritual-ritual terjadi dan bagaimanapun dilakukan, tindakan pemujaan kultikultural itu adalah hal yang paling penting. 
Sistem masyarakat dalam melaksanakan upacara mamapas lewu akibat perzinahan mempunyai berbagai simbol yang mempunyai fungsi yang bertujuan untuk menciptakan keseimbangan, keharmonisan dan keselamatan dunia. Sesuai teori Fungsionalisme Struktural dan konsep pratika dalam ajaran agama Hindu, upacara Pakanan Dahyang yang dilaksanakan oleh masyarakat Hindu Kaharingan di Desa Petak Bahandang Kecamatan Tasik Payawan Kabupaten Katingan mempunyai beberapa fungsi saling bersinergi membentuk suatu sistem yang merupakan aktualisasi dan visualisasi nilai-nilai agama dan nilainilai budaya. Upacara mamapas lewu akibat perzinahan sebagai tindakan ritual yang mempunyai fungsi religius untuk memuja Tuhan dan sesama manusia dalam hal ini suatu persembahan yang dilakukan rohaniwan (Pisor) telah banyak berkorban untuk membantu proses pelaksanaan upacara mamapas lewu akibat perzinahan dengan menggunakan berbagai sarana bersifat sakral atau profan kaya akan simbol. Sarana dan korban yang di persembahkan merupakan simbol rasa cinta dan bakti untuk memuja
Tuhan beserta manifestasinya. Sarana dan prasarana yang menjadi pusat pelaksanaan upacara mamapas lewu kibat perzinahan mempunyai simbol-simbol religius dari sifat dan perwujudan Tuhan dalam memberikan kekuatan dalam persatuan kepada manusia. Karena dengan pemujaan atau upacara manusia yajna sebagai wujud bhakti dan persembahan untuk mendekatkan hubungan kepada tuhan, sesama manusia maupun manusia dengan lingkungan. Hal tersebut sangat sesuai dengan ajaran agama Hindu konsep Tri Hita Karana yaitu terjalinnya hubungan yang harmonis antara manusia kepada Tuhan, manusia dengan sesamanya dan manusia dengan alam.

Dengan upacara ritual semacam itu berarti si pemuja, membantu mengumpulkan dan menyebarluaskan pengaruh atau kekuatan ketuhanan, pemuja berharap akan memperoleh rahmat Tuhan. Upacara yang dilakukan dengan kepercayaan dan bakti yang tinggi akan mempunyai pengaruh atau membangkitkan ketuhanan terhadap segala sesuatu yang dianggap sakral, demikian juga karena kasih Tuhan manusia akan menerima rahmatNya. 
Dalam ritual manusia melakukan pemujaan dengan doa-doa atau mantra yang memberikan vibrasi terhadap seluruh makhluk yang ada ditempat upacara yang dipuja. Pisor melakukan upacara mamapas lewu akibat perzinahan merupakan salah satu upaya untuk menetralisirkan dari pengaruh buruk yang menimpa manusia dalam kehidupan, sebagai ungkapan rasa syukur dan terima kasih karena telah diberikan keselamatan, keharmonisa dan kedamaian.

Kehidupan beragama dalam suatu masyarakat adalah salah satu sebagai alat untuk berkomunikasi kepada Tuhan Yang Maha Esa/Ranying Hatalla Langit untuk memperkuat keyakinan, norma-norma dalam kehidupan beragama, nilai-nilai kehidupan dalam masyarakat. Dengan demikian, fungsi dalam kaitannya dengan penelitian ini dapat menunjukan bagaimana, apa manfaat dan tujuan masing-masing upacara yang dimaksud sehingga tetap dilaksanakan oleh masyarakat Hindu Kaharingan di Kalimantan Tengah khususnya di Desa Petak Bahandang Kecamatan Tasik Payawan Kabupaten Katingan.
Untuk mengkaji fungsi upacara Mamapas Lewu akibat Perzinahan yang terdapat di Kalimantan Tengah khususnya di Desa Petak Bahandang Kecamatan Tasik Payawan Kabupaten Katingan, terutama mengenai kajian tentang penggunaan sarana upacara maupun berupa peralatan dan upakaranya, sudah tentu memakan waktu dan melalui proses yang cukup matang. Oleh sebab itu rangkaian upacara seperti ini tidak dapat diabaikan begitu saja. Pada setiap proses pelaksanaan dari rangkaian upacaranya, menggunakan peralatan dan sarana sesajen, yang masing-masing memiliki fungsi, baik tersendiri maupun secara kelompok.

Dalam melaksanakan upacara mamapas lewu akibat perzinahan umat Hindu Kaharingan di Kalimantan Tengah khususnya di Desa Petak Bahandang Kecamatan Tasik Payawan Kabupaten Katingan mengandung makna yang sangat mendasar dan harus dilaksanakan. Sebagaimana telah difirmankan Ranying Hatalla Langit kepada Raja Uju Hakanduang disaat mereka melaksanakan upacara balian tantulak Dahyang Baya sebagai contoh atau pedoman kepada keturunan Raja Bunu melaksanakan 
upacara mamapas lewu akibat perzinahan pada masyarakat Hindu Kaharingan di Desa Petak Bahandang Kecamatan Tasik Payawan Kabupaten Katingan, walaupun tata caranya berbeda masing-masing DAS yang ada di Kalimantan Tengah itu menjadi keunikan bagi masyarakat.

Upacara mamapas lewu akibat perzinahan dilakukan untuk mentralisirkan, membersih dan mesucikan kehidupan manusia yang mengalami musibah, agar mereka mendapakan keselamatan, keharmonisan dan kesejahteraan dalam menjalankan kehidupan yang akan datang. Fungsi upacara mamapas lewu akibat perzinahan yaitu memberikan suatu persembahan kepada para bhuta kala yang menjaga keseimbangan alam semesta, agar diberikan keselamatan, keharmonisan dan kesejahteraan, atas berkat dari Ranying Hatalla Langit atau Tuhan Yang Maha Esa melalui para leluhur (malaikatmalaikanya). Perlunya selalu berhubungan dengan para leluhur tersebut agar melindungi dan menyelamatkan mereka dari segala penderitaan dan gangguan serta berbagai malapetaka, agar hidup mereka aman, bermasyarakat dan berbangsa serta bernegara. Sedangkan fungsi sosial adalah menggambarkan bahwa manusia mencita-citakan keselarasan hidup didunia dan diakhirat. Untuk mencapai hal tersebut maka fungsi agama memegang peranan yang sangat penting dalam kehidupan bermasyarakat. Fungsi-fungsi agama tersebut juga sesuai dengan fungsi sosial upacara mamapas lewu akibat perzinahan sebagai aplikasi ajaran agama Hindu Kaharingan.

Menurut Amisran,S.Ag Ketua Majelis Kelompok Agama Hindu Kaharingan Desa Petak Bahandang menyebutkan fungsi agama dalam pengukuhan nilai-nilai yang bersumber pada kerangka acuan yang bersifat sakral, maka normanya pun dikukuhkan dengan sanksi-sanksi sakral. Dalam setiap masyarakat sanksi sakral mempunyai kekuatan memaksa istimewa, karena ganjaran hukumannya bersifat duniawi. Fungsi agama dibidang sosial adalah fungsi penentu, dimana agama menciptakan suatu ikatan bersama, baik diantara anggota-anggota masyarakat maupun kewajiban-kewajiban sosial yang membantu mempersatukan mereka. Fungsi agama sebagai sosialisasi individu, ialah individu pada saat ia tumbuh menjadi dewasa, memerlukan 
sistem nilai sebagai semacam tuntunan umum untuk mengarahkan aktivitasnya dalam masyarakat dan berfungsi sebagai tujuan akhir pembangunan kepribadiannya sebagai peningkatan "moralisasi" individu maupun moralisasi masyarakat Indonesia pada umumnya. (wawancara, 7-10-2016).

Sejalan dengan pendapat tersebut, bahwa upacara Mamapas Lewu akibat perzinahan juga merupakan pengejewantahan fungsi-fungsi agama secara umum. Diantara fungsi upacara Mamapas Lewu akibat perzinahan sebagai pengukuh nilai-nilai yang bersumber pada kerangka acuan yang bersifat sakral, karena sanksinya pun bersifat sakral. Sedangkan fungsi upacara Mamapas Lewu akibat perzinahan adalah menciptakan ikatan bersama dalam mengambil keputusan didalam mensucikan dilingkungan keluarga, dilingkungan masyarakat dengan memenuhi kewajiban-lewajiban sosial yang membantu mempersatukan mereka berdasarkan kesepakatan bersama, sehingga upacara ini dapat diwariskan kepada generasi berikutnya sebagai ikatan kekeluargaan dan kemasyarakatan.

\subsection{Makna Upacara Mamapas Lewu Akibat Perzinahan Bagi Masyarakat Hindu Kahringan}

Pada Pelaksanaan upacara Mamapas Lewu akibat perzinahan sudah tentu mempunyai sistem tersendiri. Karena upacara Mamapas Lewu akibat perzinahan ini menyangkut seluruh lapisan masyakat, maka perlu persiapanpersiapan tata cara upacara mamapas lewu akibat perzinahan dari tahap awal hingga tahap akhir, memiliki beberapa makna dan simbolisasi. Dan di dalam kajian ini akan diuraikan makna sarana pokok upacara Mamapas Lewu akibat perzinahan diantaranya :

1. Persiapan pelaksanaan upacara.

Dalam pelaksanaan upacara mamapas lewu akibat perzinahan, masyarakat bersama mantir adat bermusyawarah untuk memupakatkan pelaksanaan upacara tersebut, terutama menyangkut hewan kurbannya, apakah sistemnya secara paksaan dibunuh ataukah di beritahu kepada pihak lakilaki. Setelah ada mupakat dari masyarakat dan mantir adat barulah di lanjutkan ketahap selanjutnya. 
2. Persiapan sarana prasarana

Dalam pelaksanaan upacara mamapas lewu akibat perzinahan perlu dipersiapkan sarana prasarana serta sesajen. Adapun sarana dan prasarana serta sesajen yang harus dipersiapkan adalah sebagai berikut :

a. Amak ukan munduk manawur (tikar tempat duduk manawur)

Tikar tempat duduk manawur biasanya tikar yang terbuat dari rotan yang disebut dengan amak pasar. Tetapi kalau memang keadaan tidak memungkinkan boleh menggunakan amak yang terbuat dari purun.

b. Tambak hambaruan.

Tambak hambaruan yaitu mangkok yang diisikan beras, giling pinang tiga buah, rukun tarahan tiga buah, beras hambaruan dibungkus, serta bunga berwarna merah secukupnya.

c. Urak ice kawak ( Babi satu ekor)

Babi ini di tumbak langsung di dalam kandang darahnya didambil sedikit dimasukkan kedalam mangkuk gunanya untuk manyaki kedua panganten nanti apa bila laki-laki sudah mengaku sesuai pernyataan perempuan dan sebagian darahnya dioleskan di daun sawang untuk syarat mamapas tiap rumah orang yang bersedia menerima mamapas. Guna dari pada mamapas ini yaitu :

1) Memberitahukan kepada masyarakat setempat bahwa perempuan ini telah dihamili oleh laki-laki bernama "kumbang".

2) Membersihkan masyarakat setempat dari berbagai macam bentuk penderitaan, kemiskinan dan permasalahan.

3) Menetralisir kembali keadaan masyarakat setempat supaya tidak terulang hal-hal yang tidak diinginkan.

Babi ini gunanya sebagian untuk sesajen Pakanan Pali. Adapun bagianbagian yang diambil dari babi untuk sesajen yaitu menurut Pisor Udi yaitu :

(1). Atei (Hati)

(2). Jantung

(3). Tulang balawar 3 hela gataui (Tulang rusuk 3 bilah sebelah kanan)

(4). Baliung atei (Tulang Rawan)

(5). Bua (ginjal)

(6). Esin sapak gataui (daging paha sebelah kanan)

(7). Esin hela lengei gataui (daging tangan sebelah kanan)

(8). Esin kahang (daging Pinggang).

(9). Esin kuluk ( daging kepalanya) (semuanya di rebus). 


\section{d. Manuk ice kawak (Ayam satu ekor)}

Ayam ini di sembelih darahnya sebagian disimpan di dalam mangkuk gunanya untuk manyaki pangantin dan sebagian dioleskan di daun sawang bersamaan dengan darah babi, yang gunanya untuk mamapas. Ayam ini direbus gunanya untuk sesajen pada saat manawur ganan pali.

e. Tampung papas

Tampung papas ini terdiri dari daun sawang gagar (yang jatuh ke tanah), daun sawang belum (masih melekat di pohon).

\section{f. Dahan urak (darah babi)}

Darah babi ini gunanya ada dua yaitu : pertama untuk mamapas setiap rumah. Kedua untuk manyaki pangantin.

g. Pasah pali (Rumah tempat menyimpan sesajen)

Pasah pali ini didirikan biasanya di pinggir sungai dan sederhana yaitu cukup menggunakan tiang dari kayu bulat sebesar lengan sebanyak empat tiang dan atapnya menggunakan kain sarung lantainya menggunakan papan tipis tanpa menggunakan dinding sementara besarnya antara panjang $60 \mathrm{~cm}$ dan lebar $45 \mathrm{~cm}$. h. Baram (tuak)

i. Bari baputi

j. Bari pulut

k. Wadai cucur lime

l. Wadai apam limkawake kawak

m. Wadai gagatas lime kawak

n. Ketupat sinta telu kawak

o. Ketupat manuk telu kawak

p. Ketupat sukup telu kawak

q. Lamang lime katetek

r. Kate manuk ice kawak

s. Sipa lime

t. Ruku lime

Upacara mamapas lewu akibat perzinahan mewujudkan sebuah simbol yang mengandung makna dalam ritual yang bersifat magis, maka oleh sebab itu dapat dibedah melalui teori Simbol supaya tidak menghilangkan makna dalam upacara tersebut.

\section{Penutup}

Berdasarkan deskripsi analisis proses, fungsi dan makna tentang upacara mamapas lewu akibat perzinahan pada masyarakat Hindu Kaharingan di Desa Petak Bahandang Kecamatan Tasik Payawan Kabupaten Katingan yang telah dipaparkan di atas, ada beberapa hal penting yang dapat disimpulkan bahwa tatacara upacara mamapas lewu akibat 
perzinahan pada masyarakat Hindu Kaharingan di Desa Petak Bahandang Kecamatan Tasik Payawan Kabupaten Katingan adalah diawali dengan mempersiapkan sarana dan prasarana upacara, setelah beberapa sarana tersebut telah dipersiapkan, maka seluruh keluarga yang melaksanakan upacara tersebut bersama-sama mendirikan pash pali tersebut di pinggir sungai, hal itu dilakukan secara bergotong royong (habaring hurung) bersama masyarakat sekitarnya. Setelah itu baru upacara mamapas lewu akibat perzinahan dilaksanakan mulai dari pisor melaksanakan duduk menawur (Hataburan Bulau Urai) menuju Ganan Pali dengan mempersembahkan sesajen agar tidak mengganggu lagi.

Fungsi upacara mamapas lewu akibat perzinahan bagi masyarakat Hindu Kaharingan di Desa Petak Bahandang Kecamatan Tasik Payawan Kabupaten Katingan adalah mempunyai fungsi yang bertujuan untuk menciptakan keseimbangan, keharmonisan dan keselamatan dunia. Fungsi upacara tersebut ditinjau dari dua arah yaitu Fungsi Religius dan fungsi sosial, dari kedua fungsi tersebut mengarahkan ke hal pelaksanaan upacara ritual sebagaimana menurut fungsi religius adalah untuk memuja Tuhan dan sesama manusia dalam hal ini suatu persembahan yang dilakukan rohaniawan (Pisor) telah banyak berkorban untuk membantu proses pelaksanaan upacara mamapas lewu akibat perzinahan dengan menggunakan berbagai sarana bersifat sakral atau profan kaya akan simbol. Sedangkan fungsi sosial adalah menciptakan ikatan bersama dalam mengambil keputusan di dalam mensucikan di lingkungan keluarga, dilingkungan masyarakat dengan memenuhi kewajiban-lewajiban sosial yang membantu mempersatukan mereka berdasarkan kesepakatan bersama, sehingga upacara mamapas lewu akibat perzinahan ini dapat diwariskan kepada generasi berikutnya sebagai ikatan kekeluargaan dan kemasyarakatan. Makna upacara mamapas lewu akibat perzinahan bagi masyarakat Hindu Kaharingan di Desa Petak Bahandang Kecamatan Tasik Payawan Kabupaten Katingan, pada hakikatnya adalah sebagai perwujudan simbol-simbol ketuhanan yang mempunyai makna yang tinggi dalam hal manusia memuja kebesaran 
Tuhan beserta semua manifestasinya, karena segala yang akan terjadi dikarenakan atas kehendak Ranying Hatalla (Tuhan Yang Maha Esa). Makna tersebut dapat ditinjau dari makna sasajen dan ritualnya.

\section{Daftar Pustaka}

Agan, Tian Basir Duhung Handepang Telun. 2001. Talatah Upacara Keselamatan. Palangka Raya : MB-AHK Pusat.

Bambang, Marhijanto. 1999. Kamus Lengkap Bahasa Indonesia Masa Kini. Surabaya : Penerbit Terbit Terang. Antropologi. Jakarta : Universitas Indonesia.

O’Dea, Thomas F. 1985. Sosiologi Agama, Suatu Pengenalan Awal. Jakarta : CV. Rajawali.

Pudja, Gde dan Sidharta, Tjokorda Rai. 2002. Manawa Dharmasastra, Jakarta : Pelita Nursatama Lestari.

Riwut, Tjilik. 2003. Penyunting Nila Riwut, Maneser Panatau Tatu Hiang (Menyelami Kekayaan Leluhur). Yokyakarta : Pustaka Lima.

Tim Penyusun . 2013. Panaturan. Palangka Raya : MB-AHK Pusat .

---------------. 2013. Profil Kabupaten Katingan. Kasongan : Badan Pusat Statistik (BPS). 